\title{
Analysis of the Risk Factors for Nosocomial Bacterial Infection in Patients with COVID-19 in a Tertiary Hospital
}

This article was published in the following Dove Press journal: Risk Management and Healthcare Policy

\author{
Keping Cheng (1D' \\ Miao $\mathrm{He}^{2}$ \\ Qin $\mathrm{Shu}^{3}$ \\ Ming $\mathrm{Wu}^{3}$ \\ Cuifang Chen ${ }^{2}$ \\ Yulei Xue ${ }^{4}$
}

'Department of Infection Management, Zhongda Hospital Affiliated to Southeast University, Nanjing 210009, People's Republic of China; ${ }^{2}$ Department of Public Health, Huangshi Central Hospital, Huangshi 435000, People's Republic of China; ${ }^{3}$ Department of Infection Prevention and Control, Huangshi Traditional Chinese Medicine Hospital, Huangshi 435004, People's Republic of China; ${ }^{4}$ Department of Infectious Diseases, Jiangsu Provincial Hospital of Traditional Chinese Medicine, Nanjing 210029, People's Republic of China
Background: Infection surveillance and risk factor analysis are among the most important prerequisites for the prevention and treatment of nosocomial bacteria infections, which are the demands for both infected and non-infected patients.

Purpose: To explore the risk factors for nosocomial bacterial infection of patients with COVID-19, and further to provide a theoretical basis for scientific prevention and control of nosocomial bacterial infection.

Methods: Between 10 January 2020 and 9 March 2020, we collected data of 212 patients with COVID-19 and then explored the influence of age, gender, length of stay, use of ventilator, urinary catheterization, central venous catheterization, white blood cell (WBC) count and procalcitonin on the nosocomial bacterial infection of patients with COVID-19 by a retrospective study.

Results: There were 212 confirmed cases of COVID-19, of which 31 cases had nosocomial bacterial infections, with an incidence of $14.62 \%$. The most common types of nosocomial bacterial infections were lower respiratory tract (12 cases, 38.71\%), which was the most frequent site, followed by urinary tract (10 cases, $32.26 \%$ ), blood stream ( 7 cases, $22.58 \%$ ), upper respiratory tract ( 1 case, 3.23\%) and gastrointestinal tract infection (1 case, 3.23\%). The incidence of nosocomial bacterial infection was significantly correlated with age, arteriovenous catheterization, urinary catheterization, WBC count and procalcitonin. Moreover, multivariate analysis confirmed that WBC (OR 8.38, 95\% CI 1.07 to 65.55), procalcitonin (OR 4.92, 95\% CI 1.39 to 17.33 ) and urinary catheterization (OR $25.38,95 \%$ CI 5.09 to 126.53) were independent risk factors for the nosocomial bacterial infection of patients with COVID-19.

Conclusion: Understanding the risk factors for nosocomial bacterial infection of patients with COVID-19 and strengthening the monitoring of various susceptible factors are helpful to control the occurrence of nosocomial bacterial infection in the COVID-19 isolation wards.

Keywords: COVID-19, nosocomial bacterial infection, risk factor
Correspondence: Keping Cheng Zhongda Hospital Affiliated to Southeast University, No. 87 Dingjiaqiao, Nanjing, People's Republic of China

Email chengkeping@sina.com

\section{Introduction}

Hospital acquired infections, commonly known as nosocomial infections, are defined as medical related issues that are not associated with the patient's original diagnosis on admission into the hospital. ${ }^{1}$ Since late December 2019, an epidemic caused by novel coronavirus (2019-nCoV) infection has occurred unexpectedly in Wuhan (the capital of Hubei province), China. ${ }^{2}$ The novel coronavirus pneumonia was named Coronavirus Disease (COVID-19) on 11 February 2020 by the World Health Organization (WHO). ${ }^{3}$ It 
turns out that COVID-19, caused by novel coronavirus (SARS-CoV-2). is the fastest spreading, most extensive, and most challenging public health emergency China has encountered since the foundation of the People's Republic of China, ${ }^{4}$ therefore 31 provinces and municipalities nationwide adopted containment measures promptly, treating COVID-19 as a Class A infectious disease and activating a Level One public health emergency response in all localities. A large number of transmissions, both in nosocomial and community settings, occurred through human-to-human contact with individuals showing no or mild symptoms of COVID-19. ${ }^{5,6}$ Nowadays, COVID-19 is not only a matter in China, for it has become a threat to the health of people worldwide. Thereby, SARS$\mathrm{CoV}-2$ infection in the latent period of patients brings great challenges to medical work. A growing number of recent studies verified that the spread of various infectious diseases can be decreased by reducing the risk of hospital infection and exposure, thus reducing the risk of cross infection in hospitals. ${ }^{7,8}$ Thus, infection surveillance and risk factor analysis are among the most important prerequisites for the prevention and treatment of nosocomial bacterial infection, which are the demands for both infected and non-infected patients. Herein, we aimed to explore the exposure of risk factors and its impact on the incidence of nosocomial bacterial infection in the patients through analyzing the surveillance data of those with suspected and confirmed COVID-19 in a designated tertiary hospital, which may contribute to the prevention and control of nosocomial bacterial infection in patients with COVID-19.

\section{Methods}

\section{Setting}

The study was conducted to analyze the risk factors for nosocomial bacterial infection in a designated tertiary hospital for cases of COVID-19 in Huangshi, China. Prior to the study, written informed consent was obtained from all individual participants and from parents/legal guardians of children under the age of 18, and the study protocol was consented to by the Medical Ethics Committee of Huangshi Traditional Chinese Medicine Hospital (HSZYPJ-2020-016-01) and complied with the requirements of the Declaration of Helsinki.

\section{Diagnostic Criteria}

According to the diagnostic standard of nosocomial infection formulated by the China's Ministry of Health in $2001,{ }^{9}$ the infected cases were confirmed by the infection preventionists in those with urinary catheterization, arteriovenous intubation, endotracheal intubation, use of ventilator and other treatment measures. Community acquired infection prior to patient's original diagnosis on admission into the hospital were excluded.

\section{Data Collection}

From 10 January 2020 to 9 March 2020, detailed information from the patients involved in the present study was collected using the software of Zhejiang Xinglin Company's Hospital Infections Monitoring and Analysis System. Age, gender, hospitalization time, use of ventilator, arteriovenous intubation, urinary catheterization, white blood cell (WBC) count, and procalcitonin prior to the bacteremic episode were documented to analyse the risk factors for nosocomial bacterial infection.

\section{Statistical Analysis}

All data were analyzed by the SPSS statistic software, version 20.0 (SPSS Inc., Chicago, IL, USA). The quantitative data were described as mean \pm standard deviation, and an independent $t$-test was performed to compare continuous variables between two groups. The counting data were described by percentages, and the chi square test or precise probability method was used to compare the difference between groups. Risk factors associated with nosocomial bacterial infections among patients with COVID-19 were analyzed using bivariate analysis. Factors with $P$-value $\leq 0.05$ at bivariate analysis were considered for multivariate analysis. Measures of effect were reported using odds ratios (ORs) for both crude and adjusted analysis, followed by $95 \%$ confidence interval (CI) and $P$ value. $P<0.05$ was defined as statistically significant.

\section{Results}

\section{Risk Factors for Nosocomial Bacterial Infection of Patients with COVID-19}

From 10 January 2020 to 9 March 2020, there were 212 confirmed patients with COVID-19, of which 108 were males and 104 were females, ranging from 16 to 89 years old with an average age of $53.1 \pm 16.6$ years. There were 31 patients confirmed by bacterial isolation, with the incidence of $14.62 \%$. The most common types of nosocomial bacterial infections were lower respiratory tract (12 cases, 38.71\%), which was the most frequent site, followed by urinary tract (10 cases, 32.26\%), blood stream (7 cases, 22.58\%), upper respiratory tract (1 case, 3.23\%) and gastrointestinal tract infection (1 case, 3.23\%). Additionally, demographic, clinical 
intervention and serological equilibrium analysis of patients with COVID-19 were compared between nosocomial bacterial infection group and the control group. There were statistically significant differences of age, use of ventilator, arteriovenous intubation, urinary catheterization, WBC count and procalcitonin between the two groups (all $P<0.05$ ) (Table 1).

\section{Multivariate Analysis of Binomial Logistic Regression}

As shown in Table 2, the binary logistic regression showed that age, use of ventilator, arteriovenous intubation, urinary

Table I Characteristics of Patients with COVID-19 and Bivariate Analysis of Risk Factors Associated with Nosocomial Infection [n (\%)]

\begin{tabular}{|c|c|c|c|c|}
\hline Characteristic & $\begin{array}{l}\text { Infection } \\
\text { Group } \\
(\mathbf{N}=31)\end{array}$ & $\begin{array}{l}\text { Control } \\
\text { Group } \\
(\mathbf{N}=181)\end{array}$ & $\begin{array}{l}\chi^{2} l \\
\text { Fisher's }\end{array}$ & $P$ value \\
\hline \multicolumn{5}{|l|}{ Age (year) } \\
\hline$\leq 45$ & $4(12.90)$ & $61(33.70)$ & & \\
\hline $45 \sim 60$ & $9(29.03)$ & $61(33.70)$ & 8.6353 & 0.0133 \\
\hline >60岁 & 18(58.06) & $59(32.60)$ & & \\
\hline \multicolumn{5}{|l|}{ Gender } \\
\hline Male & $19(61.29)$ & $92(50.83)$ & 1.1613 & 0.2812 \\
\hline Female & $12(38.71)$ & $89(49.17)$ & & \\
\hline \multicolumn{5}{|c|}{$\begin{array}{l}\text { Hospitalization time } \\
\text { (days) }\end{array}$} \\
\hline$\leq 10$ & $5(16.13)$ & $37(20.44)$ & & \\
\hline $10 \sim 20$ & $14(45.16)$ & $105(58.01)$ & 4.2678 & 0.1184 \\
\hline$\geq 20$ & $12(38.71)$ & $39(21.55)$ & & \\
\hline \multicolumn{5}{|l|}{$\begin{array}{l}\text { Use of ventilator } \\
\text { (Yes/No) }\end{array}$} \\
\hline No & $23(74.19)$ & $170(93.92)$ & Fisher's & 0.0021 \\
\hline Yes & $8(25.81)$ & $11(6.08)$ & & \\
\hline \multicolumn{5}{|l|}{ Arteriovenous } \\
\hline No & $24(77.42)$ & $169(93.37)$ & Fisher's & 0.0103 \\
\hline Yes & $7(22.58)$ & $12(6.63)$ & & \\
\hline \multicolumn{5}{|c|}{$\begin{array}{l}\text { Urinary catheterization } \\
\text { (Yes/No) }\end{array}$} \\
\hline No & $17(54.84)$ & 172(95.03) & Fisher's & $<0.0001$ \\
\hline Yes & $14(45.16)$ & $9(4.97)$ & & \\
\hline \multicolumn{5}{|l|}{ WBC $\left(\times 10^{9} / 1\right)$} \\
\hline$\leq 4.0$ & $2(6.45)$ & $54(29.83)$ & & \\
\hline $4.0 \sim 10.0$ & $20(64.52)$ & $111(61.33)$ & 15.5214 & 0.0004 \\
\hline$\geq 10.0$ & $9(29.03)$ & $16(8.84)$ & & \\
\hline \multicolumn{5}{|l|}{ РCT (ng/mL) } \\
\hline$\leq 0.1$ & $4(12.90)$ & $77(42.54)$ & 9.9791 & 0.0016 \\
\hline$>0.1$ & $27(87.10)$ & $104(57.46)$ & & \\
\hline
\end{tabular}

Abbreviations: WBC, white blood cell; PCT, procalcitonin. catheterization, WBC count and procalcitonin were the risk factors for the nosocomial bacterial infection of patients with COVID-19. Simultaneously, multiple logistic regression analysis revealed that urinary catheterization, WBC, and procalcitonin are the independent risk factors for the nosocomial bacterial infection of patients with COVID-19 after adjusting for the factors of age, use of ventilator and venous catheterization. The nosocomial bacterial infection rate in patients with urinary catheterization was 25.38 times more than that in those without urinary catheterization (95\% CI 5.09 to 126.53). The nosocomial bacterial infection rate was 8.38 times for those with WBC $\left(>10.0 \times 10^{9} / 1\right.$ or $\left.\leq 4.0 \times 10^{9} / 1\right)(95 \%$ CI 1.07 to 65.55$)$ compared with those with WBC (4.0 10.0) x $10^{9} / 1$. In addition, the nosocomial bacterial infection rate in patients with procalcitonin $>0.1$ $\mathrm{ng} / \mathrm{mL}$ was 4.92 times more than that in those with procalcitonin $\leq 0.1 \mathrm{ng} / \mathrm{mL}$ (95\% CI 1.39 to 17.33) (Table 2).

\section{Discussion}

Nosocomial infections constitute one of the main causes of morbidity and mortality in hospitalized patients with significant rise in hospital costs, ${ }^{10}$ especially those with COVID-19. ${ }^{11} \mathrm{Up}$ to now, accumulating literatures have documented that the incidence of nosocomial infections ranged from $3.6 \%$ to $12.0 \%$ in high-income countries and $5.7 \%$ to $19.1 \%$ in low- and middle-income countries. ${ }^{12-14}$ There were 212 confirmed cases of COVID-19 in the current study, of which 31 cases had nosocomial bacterial infection, with an incidence of $14.62 \%$. The result was similar to a report (12.5\%) in a tertiary hospital in Beijing, China. ${ }^{14}$ In a similar data study, it has been recently reported in a rapid review and meta-analysis of 40 studies that the proportion of nosocomial bacterial infection in the patients with COVID-19 was $44.0 \%$ in the early outbreak. ${ }^{11}$ There are many possible reasons contributing to the different rate of nosocomial infection among hospitals including various sample sizes, types of population, hospital facilities and management level. Notably, at the beginning of the COVID-19 epidemic in Wuhan, medical resources were scarce, and various protective measures and management of hospitals were not in place, resulting in a high rate of nosocomial infections, especially the SARS-CoV-2. ${ }^{11}$ The age of the confirmed patients with COVID-19 ranges from 16 to 89 years old with an average age of $53.1 \pm 16.6$ years, most of them are old and have a poor immune response to infection, which is similar to a previous study that, among 1482 patients hospitalized with COVID-19, $74.50 \%$ were aged $\geq 50$ years, and 
Table 2 Multivariate Analysis of Risk Factors for Nosocomial Infection in Patients with COVID-I9

\begin{tabular}{|c|c|c|c|c|c|}
\hline Variable & EV & SE & Wald $\chi^{2}$ & $P$ value & OR $(95 \% \mathrm{CI})$ \\
\hline Age ( $45 \sim 60$ years vs $\leq 45$ years) & 0.24 & 0.68 & 0.1299 & 0.7186 & $\mathrm{I} .28(0.34-4.8 \mathrm{I})$ \\
\hline Age ( $>60$ years vs $\leq 45$ years) & 0.23 & 0.67 & 0.1187 & 0.7304 & $1.26(0.34-4.72)$ \\
\hline Use of ventilator (Yes vs No) & -0.04 & 0.87 & 0.0019 & 0.9657 & $0.96(0.17-5.32)$ \\
\hline Arteriovenous intubation (Yes vs No) & -1.41 & 1.04 & 1.8379 & 0.1752 & $0.24(0.03-1.88)$ \\
\hline Urinary catheterization (Yes vs No) & 3.23 & 0.82 & |5.567| & 0.0001 & $25.38(5.09-126.53)$ \\
\hline WBC $\left([4.0 \sim 10.0] \times 10^{9} / /\right.$ vs $\left.\left[4.0 \times 10^{9} / /\right]\right)$ & 1.81 & 0.89 & 4.1640 & 0.0413 & $6.09(1.07-34.52)$ \\
\hline WBC $\left(\geq 10.0 \times 10^{9} / /\right.$ vs $\left.\leq 4.0 \times 10^{9} / 1\right)$ & 2.13 & 1.05 & 4.1020 & 0.0428 & $8.38(1.07-65.55)$ \\
\hline РСТ $(>0.1 \mathrm{ng} / \mathrm{mL}$ vs. $\leq 0.1 \mathrm{ng} / \mathrm{mL})$ & 1.59 & 0.64 & 6.1340 & 0.0133 & $4.92(1.39-17.33)$ \\
\hline
\end{tabular}

Abbreviations: EV, estimated value; SE, standard error; WBC, white blood cell; PCT, procalcitonin.

$54.40 \%$ were male. $^{15}$ Retrospective analysis of 212 patients with COVID-19 found that the main area of nosocomial bacterial infection was the respiratory tract, especially the lower respiratory tract, and its constituent ratio was significantly higher than that of other parts, which was consistent with the relevant research results, both at home and abroad, that most of the infection cases were concentrated in the ICU. ${ }^{16-18}$ It is suggested that the hospital should strengthen the targeted monitoring of key departments and key parts, and adopt effective prevent and control infection measures.

Bacteria are the most common pathogens responsible for nosocomial infections. A series of studies indicated that surgery, device utilization, antimicrobial use and length of stay were the risk factors for nosocomial infection. ${ }^{19-21}$ Studying the risk factors in the patients with COVID-19, bivariate analysis showed that there were six factors associated with nosocomial bacteria infection, including age, arteriovenous catheterization, urinary catheterization, use of ventilator, WBC and procalcitonin. During the hospitalization of elderly patients, many factors can interact and lead to the occurrence of nosocomial infection, ${ }^{22}$ for most of the old hospitalized patients underlying chronic basic diseases make them a high-risk population, becoming prone to nosocomial bacteria infection. ${ }^{23}$ Thereby, the elderly should be taken as the key object of nosocomial infection prevention and control.

Patients with nosocomial bacteria infections suffered a prolonged stay, during which they occupied scarce beddays and required additional diagnostic and therapeutic interventions. ${ }^{24}$ In our current study, the total hospitalization time ( $\geq 20$ days) for the patients with nosocomial bacteria infection was longer than those without, whereas that ( $\leq 10$ days or 10 20 days) for the patients with nosocomial bacteria infection was shorter than those without, but there was no statistically significant difference between the two groups. The reason may be related to the smaller sample sizes and longer hospitalization time for the new confirmed cases of COVID-19.

Invasive diagnosis and treatment not only lead the outside microorganisms into the body, but also damage the body's natural defense barrier, subsequently making it easy for pathogens to invade the body. Accumulating results verified that the use of ventilator and arteriovenous catheterization was associated with an invasive medical device or invasive procedure, which are independent risk factors for nosocomial bacteria infection. ${ }^{20,25}$ The results of this study showed that the probability of nosocomial bacteria infection increased in patients using a ventilator. Intravenous catheterization can lead to colonization as well as a broad spectrum of infections ranging from catheter site infections to catheter-related blood stream infections. ${ }^{26}$ Our present study demonstrated the proportion of bloodstream infections $(22.58 \%)$ was much higher than the average for China $(2.65 \%),{ }^{27}$ which might be related to the hospital's new policy encouraging blood cultures to enhance the detection rate of the microbiology test. Considering the increasing rates of nosocomial bacteria infection it is urgent to develop guidelines for the sterilization and disinfection of invasive devices and medical instruments used for surgeries. ${ }^{28}$

Previous studies indicated that surgery, device utilization, antimicrobial use and length of stay were the risk factors for nosocomial bacteria infection. ${ }^{1,20,21}$ Following the bivariate analysis, factors with $P$-value $\leq 0.05$ at bivariate analysis were considered for multivariate analysis. After adjustment for age, use of ventilator and arteriovenous intubation, the logistics regression model with multiple factors showed that urinary catheterization, WBC count and procalcitonin could be considered as 
independent factors for nosocomial bacteria infection in the patients with COVID-19.

The strength of association between exposure and disease is quantified by the odds ratio in case control studies (or the relative risk for cohort studies), with a 95\% confidence interval. Indwelling urinary catheters were placed in up to $25.00 \%$ of hospitalized patients and prolonged catheterization is the most important risk factor for the hospitalacquired urinary tract infection, ${ }^{29}$ accounting for $26.90 \%$ of nosocomial bacteria infection during that period of neurological ICU. ${ }^{30}$ In our present study, the nosocomial bacteria infection rate in patients with urinary catheterization was 25.38 times more than that in those without urinary catheterization (95\% CI 5.09 to 126.53). Apart from the disconnection of the catheter and the urine-collection system, and the microbial contamination arising from insertion of the catheter through the two extraluminal and the intraluminal routes. $^{31,32}$ Thereby, standardized interventions for the patients with COVID-19 is required to effectively prevent catheter-related urinary tract infection, thereby reducing the incidence of hospital-acquired bacteria infections.

Traditionally, WBC is an index for clinical monitoring of infection, which can directly resist the invasion of pathogenic microorganisms in the body. Of note, the nosocomial bacteria infection rate was 8.38 times for those with WBC $\left(>10.0 \times 10^{9} / 1\right.$ or $\left.\leq 4.0 \times 10^{9} / 1\right)$ compared with those with WBC [(4.0 10.0) x $\left.10^{9} / 1\right]$ (95\% CI 1.07 to 65.55). However, the specificity of WBC in the diagnosis of infection is low due to its vulnerability to age, gender, stress, physiology, immune status and other factors, so it should be considered comprehensively in the diagnosis of nosocomial infection. More importantly, procalcitonin has been extensively investigated in differentiation between bacterial infection and systematic inflammatory response syndrome of noninfectious origin, ${ }^{33}$ and it was recognized as an important indicator of bacterial infection owing to its clear correlation with positive blood culture. ${ }^{34,35}$ The nosocomial bacteria infection rate in patients with procalcitonin $>0.1 \mathrm{ng} /$ $\mathrm{mL}$ was 4.92 times more than that in those with procalcitonin $\leq 0.1 \mathrm{ng} / \mathrm{mL}$ (95\% CI 1.39 to 17.33 ). However, it is worth noting that procalcitonin was helpful in recognizing Gram-negative bloodstream infections, and the results should be carefully interpreted with the full knowledge of the patients' medical condition.

Apart from the self-defense capability of hospitalized patients themselves, the iatrogenic factors, including the application of hormones, cytotoxic drugs and radiation therapy as well as the abuse of antibacterial drugs, are prone to the development of nosocomial bacteria infections. Account for the considerable uncertainty brought by COVID-19, for which there is no specific drug treatment available at that time, only with individualized treatment. As a matter of fact, it was difficult to collect and classify the data of personalized treatment. Of note, some other risks, including pre-existing diseases, use of oxygen therapy from admission, and hemodialysis, may also enable nosocomial infection development, which should be a limitation of the present study. Nevertheless, development of a surveillance process to monitor this rate is an essential first step to identify local problems and priorities, and evaluate the effectiveness of bacteria infection control activity. Considering the diversity and complexity of risk factors for nosocomial bacteria infection in patients with COVID-19, medical staff should strengthen the personnel training, strictly manage the implementation of aseptic technology, reduce the invasive operation, and reasonably use antibiotics. Simultaneously, hospitals should pay special attention to the systematic monitoring and controlling of the risk factors of high-risk departments, especially for elderly patients with risk factors.

\section{Conclusion}

Understanding the risk factors for nosocomial bacteria infection in patients with COVID-19 and strengthening the monitoring of various susceptibility factors are helpful to control the occurrence of nosocomial bacteria infection in COVID-19 isolation wards.

\section{Acknowledgments}

The authors would like to thank senior engineer Guohua Xia for his kind help in the manuscript processing.

\section{Author Contributions}

All authors contributed to data analysis, drafting or revising the article, have agreed on the journal to which the article will be submitted, gave final approval of the version to be published, and agreed to be accountable for all aspects of the work.

\section{Funding}

This work was supported by the China Center for Disease Control and Prevention [No. 2019, 458], and National Nature Science Foundation of China [No. 6525000051]. 


\section{Disclosure}

The authors report no conflicts of interest in this work.

\section{References}

1. Raghavendrarao M, Abrar K, Dilip M, et al. Prevalence and risk factors for hospital-acquired infections "clean case is safer care". IJRSR. 2020;11:38021-38028. doi:10.24327/ijrsr.2020.1104.5227

2. Zhu N, Zhang DY, Wang WL, et al. A novel coronavirus from patients with pneumonia in China, 2019. $N$ Engl $J$ Med. 2020;382:727-733. doi:10.1056/NEJMoa2001017

3. World Health Organization. WHO director-general's remarks at the media briefing on 2019-nCov on 11 February 2020[EB/OL]. Available from: https://www.who.int/dg/speeches/detail/who-director-general -s-remarks-at-the-media-briefing-on-2019-ncov-on-11-february-2020. Accessed October 31, 2020.

4. Lai WD, Deng ZX. The influence and countermeasures of the "COVID-19" on the economic development of coastal economic zone of guangdong province. IJEBO. 2020;8:44-48. doi:10.11648/j. ijebo.20200802.14

5. Wang YX, Chen YY, Qin QS, Qin Q. Unique epidemiological and clinical features of the emerging 2019 novel coronavirus pneumonia (COVID-19) implicate special control measure. J Med Virol. 2020;92:568-576. doi:10.1002/jmv.25748.

6. Giordano G, Blanchini F, Bruno R. Modelling the COVID-19 epidemic and implementation of population-wide interventions in Italy. Nat Med. 2020;26:855-860. doi:10.1038/s41591-020-0883-7

7. Markwell H, Godkin D. Visitor restrictions during a public health emergency: ethical issues and guidelines for policy development. MOHLTC. 2004.

8. Currie K, Curran E, Strachan E, Bunyan D, Price L. Temporary suspension of visiting during norovirus outbreaks in NHS Boards and the independent care home sector in Scotland: a cross-sectional survey of practice. J Hosp Infect. 2016;92:253-258. doi:10.1016/j. jhin.2015.10.018.

9. Ministry of Health of the People's Republic of China. Diagnostic criteria for nosocomial infections (proposed). Natl Med J China. 2001;81:314-320. doi:10.3760/oma.j.issn.0376-2491.2001.05.027

10. Cassini A, Plachouras D, Eckmanns T, et al. Burden of six health care associated infections on European population health: estimating incidence based disability-adjusted life years through a population prevalence-based modelling study. PLoS Med. 2016;13:e1002150. doi:10.1371/journal.pmed.1002150.

11. Zhou Q, Gao Y, Wang X, et al. Nosocomial infections among patients with COVID-19, SARS and MERS: a rapid review and meta-analysis. Ann Transl Med. 2020;8:629. doi:10.21037/atm-203324.

12. Schröder C, Schwab F, Behnke M, et al. Epidemiology of healthcare associated infections in Germany: nearly 20 years of surveillance. Int $J$ Med Microbiol. 2015;305:799-806. doi:10.1016/j. ijmm.2015.08.034.

13. Michihiko G, Ohl ME, Schweizer ML, Perencevich EN. Accuracy of administrative code data for the surveillance of healthcare- associated infections: a systematic review and meta-analysis. Clin Infect Dis. 2013;58:688-696. doi:10.1093/cid/cit737.

14. Zhang Y, Du M, Johnston J, et al. Incidence of healthcare-associated infections in a tertiary hospital in Beijing, China: results from a real-time surveillance system. Antimicrob Resist Infect Control. 2019;8:145. doi:10.1186/s13756-019-0582-7.

15. Garg S, Kim L, Whitaker M, O'Halloran A, Fry A. Hospitalization rates and characteristics of patients hospitalized with laboratory-confirmed coronavirus disease 2019 -COVID-NET, 14 States. MMWR Morb Mortal Wkly Rep. 2020;69:458-464. doi:10.15585/mmwr.mm6915e3
16. Zhang Y, Zhang J, Wei D, et al. Annual surveys for point-prevalence of healthcare-associated infection in a tertiary hospital in Beijing, China, 2012-2014. BMC Infect Dis. 2016;16:1-7. doi:10.1186/ s12879-016-1504-4

17. Wu YL, Yang XY, Pan MS, et al. An 8-year point-prevalence surveillance of healthcare-associated infections and antimicrobial use in a tertiary care teaching hospital in China. Epidemiol Infect. 2018;147:1-6. doi:10.1017/S0950268818002856

18. Kumar A, Biswal M, Dhaliwal N, et al. Point prevalence surveys of healthcare-associated infections and use of indwelling devices and antimicrobials over three years in a tertiary care hospital in India. $J$ Hosp Infect. 2014;86:272-274. doi:10.1016/j. jhin.2013.12.010

19. Yallew WW, Kumie A, Yehuala FM. Point prevalence of hospital-acquired infections in two teaching hospitals of Amhara region in Ethiopia. Drug Healthc Patient Saf. 2016;8:71-76. doi:10.2147/DHPS.S107344

20. Worku YW, Abera K, Moges YF, Folgori L. Risk factors for hospital-acquired infections in teaching hospitals of Amhara regional state, Ethiopia: a matched-case control study. PLoS One. 2017;12: e0181145. doi:10.1371/journal.pone.0181145

21. Meric M, Baykara N, Aksoy S, et al. Epidemiology and risk factors of intensive care unit-acquired infections: a prospective multicentre cohort study in a middle-income country. Singap Med J. 2012;53:260-263. doi:10.1186/s12879-019-3772-2.

22. Islam T, Kubra K, Chowdhury MMH. Prevalence of methicillin-resistant staphylococcus aureus in hospitals in Chittagong, Bangladesh: a threat of nosocomial infection. $J$ Microsc Ultrastruct. 2018;6:188-191. doi:10.4103/JMAU.JMAU_33_18.

23. Li H, Liu Z, Ge JB. Scientific research progress of COVID-19/ SARS-CoV-2 in the first five months. $J$ Cell Mol Med. 2020;24:6558-6570. doi:10.1111/jcmm.15364.

24. Sáez-Castillo AJ, Olmo-Jiménez MJ, Sánchez JMP, Hernández MÁN, Arcos-Navarro Á, Díaz-Oller J. Bayesian analysis of nosocomial infection risk and length of stay in a department of general and digestive surgery. Value Health. 2010;13:431-439. doi:10.1111/j.1524-4733.2009.00680.x.

25. Xu Y, Lai CY, Xu GG, Meng WW. Risk factors of ventilator-associated pneumonia in elderly patients receiving mechanical ventilation. Clin Interv Aging. 2019;14:1027-1038. doi:10.2147/CIA.S197146.

26. Aktaş E, Sarı EN, Seremet KA, Pişkin N, Külah C, Cömert F. Causative agents of intravenous catheter-related infections and their antibiotic susceptibilities. Mikrobiyol Bul. 2011;45:86-92. doi:10.1099/mic.0.042549-0.

27. Wang J, Liu F, Tartari E, et al. The prevalence of healthcare-associated infections in mainland China: a systematic review and meta-analysis. Infect Control Hosp Epidemiol. 2018;39:701-709. doi:10.1017/ice.2018.60

28. Gould CV, Umscheid CA, Agarwal RK, Kuntz G, Pegues DA. Healthcare infection control practices advisory committee guideline for prevention of catheter-associated urinary tract infections. Infect Control Hosp Epidemiol. 2020;31:319-326. doi:10.1086/ 651091

29. Saint SS, Kaufman AR, Thompson M, Rogers MAM, Chenoweth CE. A reminder reduces urinary catheterization in hospitalized patients. Joint Comm J Qual Patient Saf. 2005;31:455-462.

30. Wang F, Xing T, Li JH, He YZ, Bai M, Wang NS. Survey on hospital-acquired urinary tract infection in neurological intensive care unit. Apmis. 2013;121:197-201. doi:10.1111/j.1600-0463. 2012.02956.x

31. Reiche T, Lisby G, Jørgensen S, Christensen AB, Nordling J. A prospective, controlled, randomized study of the effect of a slow-release silver device on the frequency of urinary tract infection in newly catheterized patients. BJUI. 2000;85:54-59. doi:10.1046/ j.1464-410x.2000.00408.x 
32. Mohajer MA, Darouiche RO. Prevention and treatment of urinary catheter- associated infections. Curr Infect Dis Rep. 2013;15:116-123. doi:10.1007/s11908-013-0316-6

33. Davies J. Procalcitonin. JCP. 2015;68:675-679.

34. Luo X, Chen S, Zhang J, et al. Procalcitonin as a marker of Gram-negative bloodstream infections in hematological patients with febrile neutropenia. Leuk Lymphoma. 2019;60:2441-2448. doi:10.1080/10428194.2019.1581928.
35. Amanda W, Nicholas K, Tej S, et al. Serum procalcitonin level is associated with positive blood cultures, in-hospital mortality, and septic shock in emergency department sepsis patients. Cureus. 2020;12:12. doi:10.7759/cureus.7812.

\section{Publish your work in this journal}

Risk Management and Healthcare Policy is an international, peerreviewed, open access journal focusing on all aspects of public health, policy, and preventative measures to promote good health and improve morbidity and mortality in the population. The journal welcomes submitted papers covering original research, basic science, clinical \& epidemiological studies, reviews and evaluations, guidelines, expert opinion and commentary, case reports and extended reports. The manuscript management system is completely online and includes a very quick and fair peer-review system, which is all easy to use. Visit http://www.dovepress.com/testimonials.php to read real quotes from published authors.

Submit your manuscript here: https://www.dovepress.com/risk-management-and-healthcare-policy-journal 